\title{
Psychological well-being and perceived financial performance: An SME perspective
}

\author{
S.M. Farrington * \\ Nelson Mandela University, South Campus, PO Box 77 000, Port Elizabeth, 6031, South Africa \\ *To whom all correspondence should be addressed \\ shelley.farrington@mandela.ac.za
}

\begin{abstract}
Psychological well-being is influenced by the "surrounding contexts of people's lives" and has consistently been found to be associated with positive outcomes. Given the turbulent surrounding contexts facing SME owners in South Africa, the primary objective of this study was to investigate their level of psychological well-being and to establish the influence thereof on the financial performance of their businesses. A survey using a structured questionnaire was used to gather the necessary data. The population consisted of all owners of SMEs operating within the borders of the Eastern Cape province of South Africa. Criterion and convenience sampling were used and questionnaires were administered by field workers. In total 495 questionnaires were useable for statistical analysis. Scale validity and reliability was assessed, descriptive statistics calculated and Pearson's product moment correlations established. Multiple regression analysis was undertaken to investigate the hypothesised relationships. The results show that the participating SME owners have high levels of positive psychological well-being and that their businesses are performing financially. The results also suggest that the more SME owners display the attributes associated with environmental mastery, self-acceptance and autonomy, the more likely their SMEs are to perform financially.
\end{abstract}

\section{Introduction}

During the past year, South Africa as a country has faced turbulent times. In addition to the constant threats associated with high unemployment, labour, service delivery and student protests, electricity shortages and high crime, the threats posed by a volatile exchange rate, possible downgrade to junk status, rising inflation, low commodity prices, political uncertainty, and the worst drought in two decades, have been ever present. Not surprisingly consumer and business confidence are low and continue to restrain economic growth in the country (Techcentral, 2016). As it is, the failure rate of small and medium-sized enterprises (SMEs) in South Africa is high (Fatoki, 2014). Operating in an environment characterised by the aforementioned threats can only exacerbate this failure rate, not only directly in terms of operating constraints and reduced profits, but also indirectly in terms of the psychological well-being of SME owners.

Keyes, Shmotkin and Ryff (2002: 1007) describe psychological well-being as the "perception of engagement with existential challenges of life", whereas Deci and Ryan (2008) cited in Winefield, Gill, Taylor and Pilkington (2012: 2) describe it as "some combination of positive affective states such as happiness and functioning with optimal effectiveness in individual and social life". According to Ryff and Singer (2006: 14), psychological well-being is "profoundly influenced by the surrounding contexts of people's lives". Furthermore, optimum levels of psychological well-being are likely to depend on an individual's external circumstances as well as the resources and challenges they face (Huppert, 2009; Oishi, Diener \& Lucas, 2007).

Psychological well-being has been investigated in various organisational contexts, including employee well-being (Žižek, Treven \& Čančer, 2015; Srimathi \& Kiran Kumar, 2010), engagement (Kanten \& Yesiltas, 2015; Robertson \& Cooper, 2010) and job satisfaction (Jones, Hill \& Henn, 2015; Wright \& Cropanzano, 2000), as well as work-family relationships (Carr, 2004; Carr, 2002; Grzywacz \& Butler, 2005). Some studies on psychological well-being have been found in the context of entrepreneurship (Uy, Foo \& Song, 2013; Parasuraman, Purohit \& Godshalk, 1996), but a search of over 700 studies employing Ryff's (1989) scale of psychological well-being found no reference to studies in the context of small business (Ryff's scale information document, 2016).

Psychological well-being has been found to be associated with positive outcomes. Wright and Cropanzano (2000) highlight that the benefits of psychological well-being include an increase in cognitive functioning and the health of an individual; and ultimately the happy functioning of society as a whole. In general psychological well-being is seen as necessary for effective overall human functioning (Ryan \& Deci, 2001). Robertson and Cooper (2010) found that individuals who possess higher levels of psychological wellbeing behave in ways that would be expected to lead to higher levels of engagement in the workplace, which in turn impacts on business success. Against this background, one can suggest that SME owners who display a positive psychological well-being are more likely to contribute to positive outcomes, such as successful businesses. Therefore, 
the purpose of this study was to establish whether the psychological well-being of SME owners influences the success of their businesses. Ryff (1989) developed a theoretical model for psychological well-being describing the construct as consisting of six dimensions namely, autonomy, environmental mastery, personal growth, positive relations with others, purpose in life, and self-acceptance. It is these dimensions that are investigated in this study. More specifically the primary objective was to investigate the level of psychological well-being of SME owners in terms of the six dimensions and to establish the influence thereof on the financial performance of their businesses. To achieve this objective, the research questions are posed as follows: Do SME owners display psychological well-being? Do higher levels of psychological well-being among SME owners lead to businesses that perform financially better?

This study shows that despite turbulent times being experienced in South Africa, the SME owners participating perceive themselves as having high levels of positive psychological well-being and that their businesses are performing financially. Furthermore, the more SME owners display the attributes associated with the dimensions of psychological well-being namely, environmental mastery, self-acceptance and autonomy, the more likely their SMEs are to perform financially. In the paragraphs that follow a literature review will be presented and the hypotheses developed. The methodology will be described and the empirical results presented. Finally, the findings will be discussed and implications for research and practice will be highlighted.

\section{Literature review and hypotheses development}

This study draws on the resource-based view (RBV) of the firm which theorises that businesses are able to outperform others if they can develop valuable "resources or capabilities which cannot be easily imitated or substituted by their competitors" (Teece, Pisano \& Shuen, 1997 cited in Kraus, Harms \& Fink, 2011: 35). This theory suggests that SMEs whose owners possess valuable resources or capabilities should outperform those SMEs who owners do not. The entrepreneurship literature further supports this suggestion in that it is well-documented that individuals with certain attributes and capabilities are likely to be more successful entrepreneurs than those without these attributes and capabilities. For example, Islam, Khan, Obaidullah and Alam (2011) and Ahmed, Halim and Zainal (2010) report that entrepreneurial attributes such as autonomy, innovativeness, risk-taking, pro-activeness, motivation and self-efficacy are significantly related to the success of SMEs. Rauch (2000) identified the need for achievement, locus of control and innovation as key factors related to business success. Many of these entrepreneurial attributes and capabilities can be associated with the attributes describing psychological wellbeing.
Psychological well-being examines "perceived thriving visa-vis the existential challenges of life" (Keyes et al., 2002: 1007 ) and is usually conceptualised as some "combination of positive affective states such as happiness and functioning with optimal effectiveness in individual and social life" (Deci \& Ryan, 2008 cited in Winefield et al., 2012: 2). Dolan, Peasgood and White (2007: 95) describe psychological wellbeing as "the extent to which individual's preferences in life are satisfied", whereas according to Huppert (2009: 137), "psychological well-being is about lives going well. It is the combination of feeling good and functioning effectively."

An extensive body of literature encompassing several perspectives on positive psychological functioning exists (Ryff, 1989). Ryff (1989: 1070) argues that "the preceding perspectives can be integrated into a more parsimonious summary". She concluded that "when one reviews the characteristics of well-being described, it becomes apparent that many theorists have written about similar features of positive psychological functioning". It is the similar features or "points of convergence" in these prior theories that constituted the core dimensions of Ryff's alternative conceptualisation of psychological well-being (Ryff, 1989: 1070). She conceptualises psychological well-being as consisting of six core dimensions, namely autonomy, environmental mastery, personal growth, positive relations with others, purpose in life, and self-acceptance (Ryff, 1989). Her theory guided definitions of the six dimensions are summarised in Table 1 together with several examples of entrepreneurial attributes that can be associated with each dimension.

Psychological well-being is associated with positive outcomes. Positive outcomes from an individual perspective include an increase in cognitive functioning and physical health (Huppert, 2009; Wright \& Cropanzano, 2000), which in turn contribute to positive outcomes from a work perspective. Greater employee resilience, reduced absence from work, less accidents at the workplace, improved employee retention, higher employee commitment, productivity and performance, an enhanced employer brand, effective workplace relations and even owner selfsatisfaction, are all positive outcomes associated with a positive psychological well-being (Rahman, Amran, Ahmad \& Taghizadeh, 2013; Avey, Luthans, Smith \& Palmer, 2010; Bevan, 2010; Harter, Schmidt \& Keyes, 2003; Wright \& Cropanzano, 2000). Psychological well-being is seen as necessary for effective overall human functioning (Ryan \& Deci, 2001). In a work context, it is these positive outcomes that contribute to customer satisfaction and increased productivity, ultimately increasing the profitability of the business (Robertson \& Cooper, 2010; Harter et al., 2003). According to Robertson and Cooper (2010: 325), "research evidence suggests that high levels of psychological wellbeing and employee engagement play a central role in delivering some of the important outcomes that are associated with successful, high performing organisations". 
Table 1: Dimensions of psychological well-being and associated entrepreneurial attributes

\begin{tabular}{|c|c|}
\hline \multicolumn{2}{|l|}{ Self-acceptance } \\
\hline High scorer: & $\begin{array}{l}\text { Possesses a positive attitude toward the self; acknowledges and accepts multiple aspects of self, including } \\
\text { good and bad qualities; feels positive about past life. }\end{array}$ \\
\hline Low scorer: & $\begin{array}{l}\text { Feels dissatisfied with self; is disappointed with what has occurred with past life; is troubled about certain } \\
\text { personal qualities; wishes to be different than what he or she is. }\end{array}$ \\
\hline Entrepreneurial attributes: & $\begin{array}{l}\text { Self-confidence, self-efficacy (Maas \& Fox, 1997), self-management (Venter \& Urban, 2016), independence, } \\
\text { locus of control and self-reliance (Liang \& Dunn, 2008; Gurol \& Atsan, 2004; Rwigema \& Venter, 2004). }\end{array}$ \\
\hline \multicolumn{2}{|c|}{ Positive relations with others } \\
\hline High scorer: & $\begin{array}{l}\text { Has warm, satisfying, trusting relationships with others; is concerned about the welfare of others; capable of } \\
\text { strong empathy, affection, and intimacy; understands give and take of human relationships. }\end{array}$ \\
\hline Low scorer: & $\begin{array}{l}\text { Has few close trusting relationships with others; finds it difficult to be warm, open, and concerned about } \\
\text { others; is isolated and frustrated in interpersonal relationships; not willing to make compromises to sustain } \\
\text { important ties with others. }\end{array}$ \\
\hline Entrepreneurial attributes: & $\begin{array}{l}\text { Emotional intelligence, teamwork, networking and leadership (Venter \& Urban, 2016; Kaplan \& Warren, } \\
\text { 2010). }\end{array}$ \\
\hline \multicolumn{2}{|l|}{ Autonomy } \\
\hline High scorer: & $\begin{array}{l}\text { Is self-determining and independent; able to resist social pressures to think and act in certain ways; regulates } \\
\text { behaviour from within; evaluates self by personal standards. }\end{array}$ \\
\hline Low scorer: & $\begin{array}{l}\text { Is concerned about the expectations and evaluations of others; relies on judgments of others to make important } \\
\text { decisions; conforms to social pressures to think and act in certain ways. }\end{array}$ \\
\hline Entrepreneurial attributes: & Locus of control, independence and self-reliance (Bosch, Tait \& Venter, 2011). \\
\hline \multicolumn{2}{|l|}{ Environmental mastery } \\
\hline High scorer: & $\begin{array}{l}\text { Has a sense of mastery and competence in managing the environment; controls complex array of external } \\
\text { activities; makes effective use of surrounding opportunities; able to choose or create contexts suitable to } \\
\text { personal needs and values. }\end{array}$ \\
\hline Low scorer: & $\begin{array}{l}\text { Has difficulty managing everyday affairs; feels unable to change or improve surrounding context; is unaware } \\
\text { of surrounding opportunities; lacks sense of control over external world. }\end{array}$ \\
\hline Entrepreneurial attributes: & $\begin{array}{l}\text { Self-confidence (Bosch } \text { et al., 2011), problem solving ability (Rwigema \& Venter, 2004: 62) and seeking } \\
\text { opportunities (Bosch et al., 2011). }\end{array}$ \\
\hline \multicolumn{2}{|l|}{ Purpose in life } \\
\hline High $s$ & $\begin{array}{l}\text { Has goals in life and a sense of directedness; feels there is meaning to present and past life; holds beliefs that } \\
\text { give life purpose; has aims and objectives for living. }\end{array}$ \\
\hline Low scorer: & $\begin{array}{l}\text { Lacks a sense of meaning in life; has few goals or aims, lacks a sense of direction; does not see purpose of } \\
\text { past life; has no outlook or beliefs that give life meaning. }\end{array}$ \\
\hline Entrepreneurial attributes: & $\begin{array}{l}\text { Desire, drive, determination and goal orientated (Venter \& Urban, 2016; Bosch et al., 2011; Kuratko \& } \\
\text { Hodgetts, 2004). }\end{array}$ \\
\hline \multicolumn{2}{|l|}{ Personal growth } \\
\hline High scorer: & $\begin{array}{l}\text { Has a feeling of continued development; sees self as growing and expanding; is open to new experiences; has } \\
\text { sense of realising his or her potential; sees improvement in self and behaviour over time; is changing in ways } \\
\text { that reflect more self-knowledge and effectiveness }\end{array}$ \\
\hline Low scorer: & $\begin{array}{l}\text { Has a sense of personal stagnation; lacks sense of improvement or expansion over time; feels bored and } \\
\text { uninterested with life; feels unable to develop new attitudes or behaviours. }\end{array}$ \\
\hline Entrepreneurial attributes: & $\begin{array}{l}\text { Education (Rae, 2007; Rwigema \& Venter, 2004), locus of control (Liang \& Dunn, 2008; Gurol \& Atsan, } \\
\text { 2004), tolerance for ambiguity and uncertainty (Kuratko \& Hodgetts, 2004), and self-management (Venter \& } \\
\text { Urban, 2016). }\end{array}$ \\
\hline
\end{tabular}

Source: Ryff, 2014; Ryff \& Keyes, 1995

As described by Winefield et al. (2012: 2), psychological well-being it a "combination of positive affective states", and positive affect can facilitate opportunity recognition, the acquisition of resources, the development of networks, the ability to deal with highly dynamic environments and a tolerance for high levels of stress, all of which are key to entrepreneurial success (Baron, 2008). Psychological wellbeing potentially influences entrepreneurial productivity and performance and is thus vital for successful business ventures (Uy, Foo \& Song, 2013). Against this background, the following hypotheses are subjected to empirical testing in this study:
$\mathrm{H}^{1-6}$ : There is a positive relationship between the levels of Autonomy $\left(\mathrm{H}^{1}\right)$, Environmental mastery $\left(\mathrm{H}^{2}\right)$, Personal growth $\left(\mathrm{H}^{3}\right)$, Positive relations with others $\left(\mathrm{H}^{4}\right)$, Purpose in life $\left(\mathrm{H}^{5}\right)$ and Self-acceptance $\left(\mathrm{H}^{6}\right)$ displayed by SME owners and the Perceived financial performance of their businesses

\section{Methodology}

This study adopted a positivistic research paradigm and implemented a quantitative research approach which was deductive and cross-sectional in nature. A survey using a selfadministered, structured questionnaire was used to gather the necessary data. 


\section{Population and sample}

The population consisted of all owners of SMEs operating within the borders of the Eastern Cape province of South Africa. To date, there is no national database or list of small businesses in South Africa or in the Eastern Cape, therefore criterion and convenience sampling were used to identify potential respondents. An SME refers to a business that employs more than five but fewer than 200 full-time employees. These employee numbers were based on the National Small Business Amendment Act 23 of 2003 criteria (Bosch et al., 2011). In addition to the aforementioned criterion the business had to have been in operation for at least one year and the owner had to be actively involved in the daily running and managing of the business. The SME owners were the unit of analysis.

\section{Measuring instrument and data collection}

The measuring instrument consisted of a cover letter and two sections. Section A requested information about the owners of the SME and their businesses, and also included a question verifying that respondent's met the criteria for participation. In this way it was possible to minimise non-response error. Section B comprised 60 randomised statements measuring psychological well-being and the Perceived financial performance of the SME. The scale measuring psychological well-being was sourced from Ryff (1989), who development an instrument to measure six dimensions of psychological well-being, namely, Autonomy, Environmental mastery, Personal growth, Positive relations with others, Purpose in life and Self-acceptance. To measure the dependent variable, Perceived financial performance, a six item scale was also sourced from previous studies (Silwana, 2015; MatchabaHove, 2013; Eybers, 2010; Farrington, 2009). All scales used have reported satisfactory levels of validity and reliability in previous studies. The dependent variable was measured based on the owner's self-reported perceptions, labelled Perceived business performance, and operationalised as the SME being profitable, financially secure and successful as well as experiencing growth in sales, profits and employee numbers over the past three years. It is not uncommon among studies of this nature to use perceived rather than actual performance indicators to measure business performance (Mahmood \& Hanafi, 2013; Soininen, Martikainen, Puumalainen \& Kyläheiko, 2012; Lim, 2008). As per Ryff's (1989) scales, respondents in the current study were required to indicate their extent of agreement with each statement by means of a six-point Likert scale. The scale was interpreted as $1=$ strongly disagree, 2 = moderately disagree, 3 = slightly disagree, $4=$ slightly agree, $5=$ moderately agree and $6=$ strongly agree.

SME owners responded by means of self-reporting to the independent and dependent variables at the same time, and from the same measuring instrument. As such concerns are raised (Meade, Watson \& Kroustalis, 2007) relating to common method bias (CMB). Several procedural methods were implemented proactively to reduce the possibility of CMB. The items on the scale were kept simple, specific, and concise, and constructed carefully to avoid ambiguity, vagueness, and being double-barrelled (Podsakoff, MacKenzie, Lee \& Podsakoff, 2003). In addition, items were randomised (Meade et al., 2007) and respondents were assured of anonymity and also that no answers were right or wrong (Podsakoff et al., 2003).

Potential respondents were approached by fieldworkers during the months of March and April 2016 and requested to participate in the study. Five hundred and eighty-eight (588) questionnaires were personally delivered and collected upon completion. Completed questionnaires were examined to ensure that they met the criteria for participation and then captured onto an Excel sheet. The mean-substitution approach was used to replace missing values. This approach was considered suitable as the levels of missing values were very low (Hair, Black, Babin \& Anderson, 2010). Of the distributed questionnaires, 495 were useable for statistical analysis. An effective response rate of 84 per cent was achieved. Given the high response rate, non-response bias was not considered to be a problem in this study.

\section{Data analysis}

The statistical software, STATISTICA version 13 was used to perform the statistical analysis in this study. Factor analysis was used to examine the construct validity of the scales measuring the independent and dependent variables. More specifically, tests for uni-dimensionality were used. A measurement is regarded as uni-dimensional when an individual underlying trait is responsible for all common variance among item responses (Robins, Fraley \& Krueger, 2009). These tests were deemed appropriate given that the scales measuring the independent and dependent variables used in this study have been validated in previous studies. According to Ryff (2014), numerous studies in different cultural contexts provide evidence of validity and reliability for the psychological well-being scale. Principle components analysis was specified as the extraction method to produce an unrotated factor matrix. Factor loadings of greater than 0.5 (Hair, Black, Babin \& Anderson, 2014) were considered significant. Cronbach's alpha coefficients were used to assess the degree of internal reliability of the various scales. A Cronbach's alpha coefficient (CA) of 0.70 and greater was regarded as providing sufficient evidence of reliable scales (Nunnally, 1978). Thereafter, descriptive statistics were calculated to summarise the sample data and Pearson's product moment correlations to establish the correlations between the factors under investigation. Finally, multiple regression analysis was undertaken to investigate whether relationships existed between the independent (dimensions of psychological well-being) and the dependent variables (Perceived financial performance).

\section{Empirical results}

\section{Sample description}

The majority of respondents participating in this study were male $(71.72 \%)$, over the age of 40 years $(58.38 \%)$ and in 
possession of tertiary qualification $(67.68 \%)$. Just over half $(51.11 \%)$ were of the white ethnic group, followed by respondents from the Coloured (44.85\%) and Black (26.06\%) ethic groups. The majority $(59.39 \%)$ had also been the SME owner for 10 year or less. The majority of SMEs were familyowned $(56.47 \%)$, in their first generation $(75.36 \%)$, and operated in either the service $(41.62 \%)$ or retail/wholesale $(22.42 \%)$ industries. Most respondents owned SMEs that employed between 6 and 20 employees (61.62\%).

\section{Validity and reliability analyses}

As can be seen from Table 2, all the items measuring Perceived financial performance loaded together as expected. However, the items measuring the dimensions of psychological well-being did not all load as expected. Only items with factor loadings above the cut-off point of 0.5 (Hair et al., 2014) were retained. As a result, only certain items were considered significant. For the number of items loading as well as the minimum and maximum factor loadings see Table 2. Purpose in life and Autonomy returned Cronbach's alpha coefficients of 0.592 and 0.570 respectively, but were still considered for further analysis given their close proximity to 0.6 . The other factors returned Cronbach's alpha coefficients greater than the lower limit of 0.70 (Nunnally, 1978). Acceptable or satisfactory evidence of validity and reliability for the various constructs was thus provided.

Table 2: Validity and reliability results

\begin{tabular}{l|c|c|c|c}
\hline Variables & $\begin{array}{c}\text { Original } \\
\text { items }\end{array}$ & $\begin{array}{c}\text { Items } \\
\text { loadings }\end{array}$ & $\begin{array}{c}\text { Min. and } \\
\text { Max. } \\
\text { loadings }\end{array}$ & CAs \\
\hline $\begin{array}{l}\text { Perceived } \\
\text { financial } \\
\text { performance }\end{array}$ & 6 & 6 & $\begin{array}{c}-0.605 \text { to }- \\
0.820\end{array}$ & 0.809 \\
\hline $\begin{array}{l}\text { Environmental } \\
\text { mastery }\end{array}$ & 9 & 6 & $\begin{array}{c}-0.558 \text { to }- \\
0.685\end{array}$ & 0.722 \\
\hline Purpose in life & 9 & 4 & $\begin{array}{c}-0.554 \text { to }- \\
0.708\end{array}$ & $\mathbf{0 . 5 9 2}$ \\
\hline Autonomy & 9 & 5 & $\begin{array}{c}-0.563 \text { to }- \\
0.698\end{array}$ & $\mathbf{0 . 5 7 0}$ \\
\hline Personal growth & 9 & 6 & $\begin{array}{c}-0.563 \text { to }- \\
0.698\end{array}$ & 0.636 \\
\hline $\begin{array}{l}\text { Positive relations } \\
\text { with others }\end{array}$ & 9 & 5 & $\begin{array}{c}-0.589 \text { to }- \\
0.724\end{array}$ & 0.726 \\
\hline Self-acceptance & 9 & 5 & $\begin{array}{c}-0.578 \text { to }- \\
0.698\end{array}$ & 0.651 \\
\hline
\end{tabular}

As a result of the validity assessments the operational definitions of the dimensions of psychological well-being were reformulated (see Table 3). The operationalisation of Perceived financial performance remained unchanged.

\section{Data description}

Harman's single-factor test was used as the post hoc statistical technique to assess for the existence of CMB. All the items measuring all the constructs were included in the analysis. A single factor emerged explaining 16.85 percent of the variance in the data; well below the threshold of 50 per cent. This suggests that CMB is not a matter of serious concern in this study. Although the usefulness of Harman's single-factor test has been questioned (Podsakoff et al., 2003), alternative techniques also suffer from limitations and are not recommended until effectiveness has been shown (Conway \& Lance, 2010).

\section{Table 3: Operational definitions}

\begin{tabular}{l|l}
\hline Variables & Operational definitions \\
$\begin{array}{l}\text { Perceived } \\
\text { financial } \\
\text { performance }\end{array}$ & $\begin{array}{l}\text { Refers to the SME as being profitable, } \\
\text { financially secure and successful as well as } \\
\text { experiencing growth in sales, profits and } \\
\text { employee numbers over the past three years. }\end{array}$ \\
\hline Environmental \\
mastery & $\begin{array}{l}\text { Refers to a person who is in charge of and } \\
\text { satisfied with their life situation and is good } \\
\text { at managing their time as well as their daily } \\
\text { and financial responsibilities. }\end{array}$ \\
\hline \multirow{3}{*}{ Purpose in life } & $\begin{array}{l}\text { Refers to a person who tends to look to the } \\
\text { future, sees their daily activities as important, } \\
\text { values goal-setting and works towards future } \\
\text { plans. }\end{array}$ \\
\hline Autonomy & $\begin{array}{l}\text { Refers to a person whose decisions are not } \\
\text { easily influenced by others, who regards } \\
\text { happiness as more important than peer } \\
\text { approval, and judges him or herself by what } \\
\text { they value as important. }\end{array}$ \\
\hline Personal growth & $\begin{array}{l}\text { Refers to a person that embraces new } \\
\text { experiences that challenge their thinking and } \\
\text { expands their horizons, continuously strives } \\
\text { for self-improvement and sees life as a } \\
\text { process of continuous learning. }\end{array}$ \\
\hline $\begin{array}{l}\text { Positive } \\
\text { relations } \\
\text { others }\end{array}$ & $\begin{array}{l}\text { Refers to a person who has many friends and } \\
\text { is able to maintain warm and trusting } \\
\text { relationships with others. }\end{array}$ \\
\hline \multirow{2}{*}{$\begin{array}{l}\text { Refers to a person that is pleased with what } \\
\text { they have achieved and the way their life has } \\
\text { turned out, is self-confident and is positive } \\
\text { about themselves, feel they have gotten a lot } \\
\text { out of life, feel proud of their achievements } \\
\text { and have a positive attitude about themselves. }\end{array}$} \\
\hline
\end{tabular}

To undertake the inferential statistical analyses in this study the distribution of the data needed to be approximately normally distributed. The Shapiro-Wilk W test was undertaken to assess for normality, and reported the W statistic as significant $(p<0.001)$ in the case of all the factors under investigation in this study; as a result, the hypothesis that the respective distributions are normal should be rejected (StatSoft, 2013). Despite this violation, it is argued by some (Field, 2009) that when the data set is large enough, the violation of normally distributed variables does not have a significant effect (Piirala, 2012; Tabachnick \& Fidell, 2007). Hair et al. (2014) suggest that normality can have serious effects on small samples (fewer than 50 cases), but the impact effectively diminishes when samples' sizes reach 200 cases or more. Although the sample size in this study was far greater than 50, the results of the statistical analysis should be interpreted in light of this violation. Another condition necessary for undertaking inferential statistics is that of assumed equal variances (StatSoft, 2013). The results of Levene's tests were not statistically significant for any of the factors under investigation, and therefore the hypothesis of equal variances cannot be rejected (StatSoft, 2013). The 
second condition necessary for inferential statistical analysis is thus met.

\section{Descriptive statistics}

Descriptive statistics (see Table 4) were calculated to describe the sample data. For discussion purposes, response categories on the 6-point Likert scale were categorised as follows: responses from $1<=\mathrm{x}<2.667$ were categorised as disagree; $2.667<=\mathrm{x}<4.334$ categorised as neutral; and $4.334<=\mathrm{x}<=6.000$ were categorised as agree. Perceived financial performance reported a mean score of 4.889 with the majority $(73.33 \%)$ of respondents perceiving that their
SMEs were performing financially.

Purpose in life reported the highest mean score $(\bar{x}=5.108)$, followed by Personal growth $(\bar{x}=5.093)$, Environmental mastery $(\bar{x}=4.997)$ and Self-acceptance $(\bar{x}=4.987)$. The vast majority (> 80\%) of respondents agreed with the statements measuring these four dimensions. Autonomy $(\bar{x}=$ $4.566)$ and Positive relations with others $(\bar{x}=4.575)$ reported lower mean scores, and although less than the other dimensions, 63.03 percent and 64.44 percent of respondents respectively, agreed with the statement measuring these two dimensions.

Table 4: Descriptive statistics $(N=495)$

\begin{tabular}{l|c|c|c|c|c}
\hline Factor & Mean & Std. Dev & Disagree\% & Neutral\% & Agree\% \\
\hline Perceived financial performance & 4.889 & 0.859 & 2.222 & 24.444 & 73.333 \\
\hline Environmental mastery & 4.997 & 0.723 & 0.606 & 19.394 & 80.000 \\
\hline Purpose in life & 5.108 & 0.832 & 1.414 & 15.960 & 82.626 \\
\hline Autonomy & 4.566 & 0.817 & 1.414 & 35.556 & 63.030 \\
\hline Personal growth & 5.093 & 0.746 & 0.404 & 17.778 & 81.818 \\
\hline Positive relations with others & 4.575 & 1.032 & 5.859 & 29.697 & 64.444 \\
\hline Self-acceptance & 4.987 & 0.796 & 1.414 & 17.172 & 81.414 \\
\hline
\end{tabular}

\section{Pearson's product moment correlations}

From Table 5 it can be seen that the independent variables are all positively and significantly $(\mathrm{p}<0.05)$ associated with each other and that the dependent variable Perceived financial performance is positively and significantly ( $\mathrm{p}<0.05)$ associated with all the dimensions of psychological wellbeing. $\mathrm{R}$-values range between 0.175 and 0.584 .

Table 5: Pearson's correlation coefficient

\begin{tabular}{l|c|c|c|c|c|c}
\hline \multirow{2}{*}{ Variable } & \multicolumn{3}{c}{ Bold $=\mathrm{p}<0.05$} \\
\cline { 2 - 6 } & 1 & 2 & 3 & 4 & 5 & 6 \\
\hline 1 Environmental mastery & 1.000 & - & - & - & - & - \\
\hline 2 Purpose in life & $\mathbf{0 . 3 7 2}$ & 1.000 & - & - & - & - \\
\hline 3 Self-acceptance & $\mathbf{0 . 5 8 4}$ & $\mathbf{0 . 5 2 8}$ & 1.000 & - & - & - \\
\hline 4 Autonomy & $\mathbf{0 . 3 3 1}$ & $\mathbf{0 . 1 7 5}$ & $\mathbf{0 . 2 9 4}$ & 1.000 & - & - \\
\hline 5 Perceived financial performance & $\mathbf{0 . 5 2 6}$ & $\mathbf{0 . 3 2 5}$ & $\mathbf{0 . 4 2 7}$ & $\mathbf{0 . 2 6 3}$ & 1.000 & - \\
\hline 6 Personal growth & $\mathbf{0 . 2 3 9}$ & $\mathbf{0 . 5 5 6}$ & $\mathbf{0 . 3 7 7}$ & $\mathbf{0 . 1 9 7}$ & $\mathbf{0 . 2 6 1}$ & 1.000 \\
\hline 7 Positive relations with others & $\mathbf{0 . 3 0 8}$ & $\mathbf{0 . 4 1 3}$ & $\mathbf{0 . 4 4 9}$ & $\mathbf{0 . 2 0 8}$ & $\mathbf{0 . 1 7 7}$ & $\mathbf{0 . 3 3 6}$ \\
\hline
\end{tabular}

\section{Multiple regression analysis}

Before undertaking the multiple regressions analysis (MRA), variance inflation factors (VIFs) were calculated to determine whether multi-collinearity was a problem in this study. According to Craney and Surles (2002), VIFs of less than five suggest that multi-collinearity is not a problem. VIFs of less than five were reported for all the independent variables. Given the low correlations reported in Table 5 and the VIFs calculated, multi-collinearity was not considered a problem when estimating the regression model using the data collected in this study. Furthermore, to ensure that the results of a MRA are valid, several assumptions must be met. These assumptions were tested by performing a residual analysis. Both the Cook's distance method and the deleted residual method failed to identify any outliers or influential observation. The normal probability plot of the residuals only deviated somewhat from a straight line, but the normality assumption was confirmed by a histogram of the residuals. A
Durbin-Watson d value close to two (1.899) indicated that no residual serial correlation was present. The residual variance for each independent variable appears to be evenly distributed indicating that the equal variance assumption is satisfied.

From Table 6 it can be seen that the model as a whole is significant $(\mathrm{p}<0.00)$ and that the six dimensions of psychological well-being explain 32.08 per cent of the variance in Perceived financial performance. Furthermore, positive and significant relationships were reported between the dimensions, Environmental mastery $(\mathrm{p}<0.01)$, Selfacceptance $(\mathrm{p}<0.05)$ and Autonomy $(\mathrm{p}<0.01)$, and the dependent variable Perceived financial performance. As such the more the SME owners display a positive psychological well-being in terms of these dimensions the more likely they are to perceive their businesses as performing financially. Support is thus found for hypotheses $\mathrm{H}^{1}, \mathrm{H}^{2}$ and $\mathrm{H}^{6}$, but not for $\mathrm{H}^{3}, \mathrm{H}^{4}$ and $\mathrm{H}^{5}$. 
Table 6: Influence of dimensions of psychological wellbeing on Perceived financial performance

\begin{tabular}{|c|c|c|c|}
\hline \multicolumn{4}{|c|}{$\begin{array}{l}\text { Dependent variable: Perceived financial performance } \\
F(6,488)=38.420 p<0.00 ; R^{2}=0.3208\end{array}$} \\
\hline Independent variables & Beta & t-value & Sig.(p) \\
\hline Intercept & 0.8298 & 2.771 & 0.0058 \\
\hline Environmental mastery & 0.4718 & 8.410 & $0.0000 * *$ \\
\hline Purpose in life & 0.0826 & 1.593 & 0.1117 \\
\hline Self-acceptance & 0.1475 & 2.609 & $0.0094 * *$ \\
\hline Autonomy & 0.0833 & 1.973 & 0.0491* \\
\hline Personal growth & 0.0953 & 1.808 & 0.0712 \\
\hline $\begin{array}{l}\text { Positive relations with } \\
\text { others }\end{array}$ & -0.0703 & -1.948 & 0.0520 \\
\hline
\end{tabular}

$(* \mathrm{p}<0.05 ; * * \mathrm{p}<0.01)$

\section{Discussion}

The findings of this study show that despite the turbulent times experienced in South Africa, the participating SME owners perceive their businesses as profitable, financially secure and successful, as well as having experienced growth in sales, profits and employee numbers over the past three years. Furthermore, the levels of psychological well-being among them are high. The vast majority perceived themselves as people who tend to look to the future, see their daily activities as important, value goal-setting and work towards future plans (Purpose in life); as people who embrace new experiences that challenge their thinking and expand their horizons, continuously strives for self-improvement and see life as a process of continuous learning (Personal growth); as people who are in charge of and satisfied with their life situation and are good at managing their time as well as their daily and financial responsibilities (Environmental mastery); and as people who are pleased with what they have achieved and the way their life has turned out, are self-confident and positive about themselves, feel they have gotten a lot out of life, feel proud of their achievements and have a positive attitude about themselves (Self-acceptance). Although not as many as for the aforementioned dimensions, the majority of SME owners also perceived themselves as people who have many friends and are able to maintain warm and trusting relationships with others (Positive relations with others); and as people whose decisions are not easily influenced by others, who regards happiness as more important than peer approval, and judges him or herself by what they value as important (Autonomy). Given that many of the attributes associated with the dimensions of psychological well-being are associated with attributes of successful entrepreneurs, the findings of this study support the notion that entrepreneurs are generally individual with high levels of psychological well-being.

The findings also show that the dimensions, Environmental mastery, Self-acceptance and Autonomy, have a significant and positive influence on the Perceived financial performance of the SME. As such the more that SME owners demonstrate these dimensions, the more likely their SMEs are to be perceived as profitable, financially secure and successful, as well as experiencing growth in sales, profits and employee numbers over the past three years. The beta values reported in the MRA for Self-acceptance and
Autonomy, are however, very low $(<0.15)$. According to Lee (2014: 504), "in almost any standard interpretation of regression results, beta coefficients of less than 0.20 would usually not be seen to show strong linear relationships". The significant relationships reported between these two dimensions of psychological well-being and Perceived financial performance should be interpreted in light of this.

Environmental mastery reported the greatest influence on Perceived financial performance. This is not surprising given Ryff's (Ryff, 2014: 12) theoretical interpretation of Environmental mastery, namely "has a sense of mastery and competence in managing the environment; controls complex array of external activities; makes effective use of surrounding opportunities; is able to choose or create contexts suitable to personal needs and values". No significant relationships were reported between the dimensions Purpose in life, Positive relations with others and Personal growth, and dependent variable Perceived financial performance. In other words, whether SME owners display these dimensions or not, has no influence on the financial performance of their businesses.

The entrepreneurship and psychological well-being literature supports the notion that possessing certain attributes is associated with positive outcomes. Successful entrepreneurs are people who possess certain attributes, and according to Ryff (1989), people who display high levels of Environmental mastery, Self-acceptance, Autonomy, Purpose in life, Positive relations with others and Personal growth, experience high levels of psychological well-being. Both possessing entrepreneurial attributes and high levels of positive psychological well-being are associated with positive outcomes. The findings of this study support this notion for Environmental mastery, Self-acceptance and Autonomy. The more the SME owners display these dimensions of psychological well-being, the better their businesses are likely to perform financially.

It is somewhat surprising that the dimensions Purpose in life, Positive relations with others and Personal growth, have no influence on the financial performance of SMEs. People who display high levels of the aforementioned have attributes associated with successful entrepreneurs. Furthermore, it is common knowledge that people with a purpose in life, those who have good networks and relationships with others, and those who continue to develop themselves, are more likely to achieve success than those who do not. An explanation for these findings could be in the operationalisation of these constructs or in the participating sample.

\section{Implications and contributions}

The findings of this study have implications for research and practice. From the perspective of research, Ryff's (1989) scales measuring the dimensions of psychological well-being have been used and validated in numerous other studies (Ryff, 2014). Studies that have been done in different contexts and in different countries, including South Africa (Henn, Hill \& Jorgensen, 2016). Test for uni-dimentionality done in the 
current study revealed that several items did not load as expected. This raises concerns as to whether Ryff's (1989) scales are applicable to all contexts (e.g. employees and SME owners) and in all countries. The current study makes a contribution to the psychological well-being literature in that Ryff's (1989) scales were administered in the South African context and among SME owners. As far as could be established, her scales have not previously been administered among this sample group. Furthermore, this study responded to the call for more studies to be undertaken that aim "to produce a valid and reliable instrument that can measure psychological well-being in a multicultural South African society" (Henn et al., 2016: 10). The current study also makes a contribution to the entrepreneurship literature in that it highlights that successful SME owners (many of which could be entrepreneurs) also possess high levels of psychological well-being.

The findings of this study suggest that the more that SME owners display the attributes associated with Environmental mastery, as well as Self-acceptance and Autonomy (despite their low beta values reported), the more likely their businesses are to perform financially. From the perspective of practice, SME owners should thus consistently seek to develop attributes such as optimism, independence and selfconfidence; to develop their ability to manage their time and responsibilities; strive for personal fulfilment and lifesatisfaction and be proud of their achievements; have a positive attitude, live by their values and not be easily influenced by others.

\section{Limitations}

There were several limitations to this study. The responses of the SME owners were based on individual perceptions and on one-time self-report measures. According to Rauch, Wiklund, Lumpkin and Frese (2009), self-reporting can be subject to bias because of social desirability, memory deterioration and CMB. While the findings of this study do not exclude the possibility of CMB, the measures taken suggest that it is not likely to influence the interpretations of the results given. Furthermore, Meade et al. (2007) assert that the use of common assessment methods hardly necessitates large and problematic CMB. In many cases, CMB may be small and does not necessarily jeopardise the validity of the results.

The use of criterion and convenience sampling introduced a source of potential bias into the study. The findings can thus not be generalised to the entire South African SME population. According to Diener, Suh, Lucas and Smith (1999), an individual's personality, their goals, cultural values and coping efforts also influence their levels of psychological well-being. Future studies could include SMEs from other countries so that the influence of context, specifically culture and ethnicity, on the dimensions of psychological well-being and financial performance can be investigated. Furthermore, investigating aspects such as personality and the coping abilities of SME owners could provide further explanations for their levels of psychological well-being. As mentioned, all Ryff's (1989) items measuring the dimensions of psychological well-being did not load as expected in the current study. As such comparisons between other studies on psychological well-being and their interpretations are limited.

Some may also question the logic behind the directionality of the psychological well-being performance relationship investigated in this study and suggest that reverse causality is more appropriate. Such a question is justified given that in most studies on psychological well-being, well-being serves as the dependent variable (Ryff, 2014). Well-being has, however, occasionally been studied as a predictor variables (Ryff, 2014), as was the case in the current study. The author acknowledges that the financial performance of the business is likely to influence the psychological well-being of the owner. However, investigating this relationship was beyond the ambit of the current study.

Despite the limitations, this study has provided insights into the psychological well-being of SME owners in South Africa. More specifically the study highlights that despite turbulent times being experienced in the country, SME owners in South Africa display high levels of positive psychological wellbeing and their businesses are performing financially. This in itself suggests high coping abilities and highlights the resilience and tenacity of South African SME owners.

\section{References}

Ahmed, N.H., Halim, H.A. \& Zainal, S.R.M. 2010. 'Is entrepreneurial competency the silver bullet for SME success in a developing nation?', International Business Management, 4(2): 6775.

Avey, J.B., Luthans, F., Smith, R.M. \& Palmer, N.F. 2010. Impact of positive psychological capital on employee well-being over time. [online] URL: http://digitalcommons.unl.edu/cgi/ viewcontent. cgi article $=1055 \&$ context $=$ managementfacpub.

Baron, R.A. 2008. 'The role of affect in the entrepreneurial process', Academy of Management Review, 33: 328-340.

Bevan, S. 2010. 'The business case for employee's health and wellbeing', The Work Foundation, 10(1): 3-35.

Bosch, J., Tait, M. \& Venter, E. 2011. Business management: An entrepreneurial perspective. 2nd Edition. Cape Town: Lectern.

Carr, D. 2004. Psychological well-being across three cohorts: A response to shifting work-family opportunities and expectations? In Brim, O.G., Ryff, C.D. \& Kessler, C.R. (Eds.). How healthy are we? A national study of well-being at midlife. Chicago: University of Chicago Press.

Carr, D. 2002. 'The psychological consequences of work-family tradeoffs for three cohorts of men and women', Social Psychology Quarterly, 65(2): 103-124.

Conway, J.M. \& Lance, C.E. 2010. 'What reviewers should expect from authors regarding common method bias in organizational research', Journal of Business Psychology, 25: 325-334.

Craney, T.A. \& Surles, J.G. 2002. 'Model-dependent variance inflation factor cut-off values', Quality Engineering, 14(3): 391403. 
Deci, E.L. \& Ryan, R.M. 2008. 'Facilitating optimal motivation and psychological well-being across life's domains'. In Winefield, H.R., Gill, T.F., Taylor, A.W. \& Pilkington, R.M. 2012. 'Psychological well-being and psychological distress: Is it necessary to measure both?', Psychology of Well-Being, 2(3): 1-14.

Diener, E., Suh, E.M., Lucas, R.E. \& Smith, H.L. 1999. 'Subjective well-being: Three decades of progress', Psychological Bulletin, 125(2): 276-302.

Dolan, P., Peasgood, T. \& White, M. 2007. 'Do we really know what makes us happy? A review of the economic literature on the factors associated with subjective well-being', Journal of Economic Psychology, 29(1): 94-122.

Eybers, C. 2010. Copreneurships in South African small and medium-sized family businesses. Unpublished masters dissertation, Nelson Mandela Metropolitan University, Port Elizabeth, South Africa.

Farrington, S.M. 2009. Sibling partnerships in South African small and medium-sized family businesses. Unpublished doctoral thesis, Nelson Mandela Metropolitan University, Port Elizabeth, South Africa.

Fatoki, O. 2014. 'The causes of the failure of new small and medium enterprises in South Africa', Mediterranean Journal of Social Sciences, 5(20): 922-927.

Field, A.P. 2009. Discovering statistics using SPSS: And sex and drugs and rock. 3rd Edition. London: Sage.

Grzywacz, J.G. \& Butler, A. 2005. 'The impact of job characteristics on work-to-family facilitation: Testing a theory and distinguishing a construct', Journal of Occupational Health Psychology, 10(2): 97109.

Gurol, Y. \& Atsan, N. 2004. 'Entrepreneurial characteristics amongst university students: Some insights for entrepreneurship education and training in Turkey', Education and Training, 48(1): 25-38.

Hair, J.F., Black, W.C., Babin, B.J. \& Anderson, R.E. 2014. Multivariate data analysis. New International Edition. USA: Pearson.

Hair, J.F., Black, W.C., Babin, B.J. \& Anderson, R.E. 2010. Multivariate data analysis. 7th Edition. USA: Pearson.

Harter, J.K., Schmidt, F.L. \& Keyes, C.L.M. 2003. Well-being in the workplace and its relationship to business outcomes: A review of the Gallup studies. In Keyes, C.L.M. \& Haidt, J. (Eds.). Flourishing: Positive psychology and the life well-lived. Washington, DC: American Psychological Association.

Henn, C.M., Hill, C. \& Jorgensen, L.I. 2016. 'An investigation into the factor structure of the Ryff Scales of psychological well-being', SA Journal of Industrial Psychology, 42: 12-pages.

Huppert, F.A. 2009. 'Psychological well-being: Evidence regarding its causes and consequences', Applied Psychology: Health and WellBeing, 1(2): 137-164.

Islam, A., Khan, M.A., Obaidullah, A.Z.M. \& Alam, M.S. 2011. 'Effect of entrepreneur and firm characteristics on the business success of small and medium enterprises (SMEs) in Bangladesh', International Journal of Business and Management, 6(3): 289-299.
Jones, N., Hill, C. \& Henn, C. 2015. 'Personality and job satisfaction: Their role in work-related psychological well-being', Journal of Psychology in Africa, 25(4): 297-304.

Kanten, P. \& Yesiltas, M. 2015. 'The effects of positive and negative perfectionism on work engagement, psychological well-being and emotional exhaustion', Procedia Economics and Finance, 23(2015): $1367-1375$.

Kaplan, J.M. \& Warren, A.C. 2010. Patterns of entrepreneurship management. 3rd Edition. New Jersey: Wiley.

Keyes, C.L.M., Shmotkin, D. \& Ryff, C.D. 2002. 'Optimising wellbeing: The empirical encounter of two traditions', Journal of Personality and Social Psychology, 82(1): 1007-1022.

Kuratko, D.F. \& Hodgetts, R.M. 2004. Entrepreneurship: Theory, process, practice. 6th Edition. Ohio: Thomson.

Lee, G. 2014. 'Seeking rigor in South African business research: Aspirational principles in contrast to a recent publication', South African Journal of Economics and Management Sciences, 17(4): 501-514.

Liang, C. \& Dunn, P. 2008. 'Are entrepreneurs optimistic, realistic, both or fuzzy? Relationship between entrepreneurial traits and entrepreneurial learning', Academy of Entrepreneurship Journal, 14(1): 51-73

Lim, S. 2008. Entrepreneurial orientation and the performance of service businesses. [online] URL: http://www.decisionsciences.org/ Proceedings/DSI2008/docs/392-9586.pdf.

Maas, G.J.P. \& Fox, W. 1997. Entrepreneurship and public management. 1st Edition. Kenwyn: Juta.

Mahmood, R. \& Hanafi, N. 2013. 'Entrepreneurial orientation and business performance of women-owned small and medium enterprises in Malaysia: Competitive advantage as a mediator', International Journal of Business and Social Science, 4(1): 82-90.

Matchaba-Hove, M.T.M. 2013. The entrepreneurial orientation of small businesses in the Eastern Cape. Unpublished Masters dissertation, Nelson Mandela Metropolitan University, Port Elizabeth, South Africa.

Meade, A.W., Watson, A.M. \& Kroustalis, S.M. 2007. Assessing common methods bias in organizational research. ' $22^{\text {nd }}$ Annual Meeting of the Society for Industrial and Organizational Psychology', April 27-29, New York

Nunnally, J.C. 1978. Psychometric theory. 2nd Edition. New York: McGraw-Hill.

Oishi, S., Diener, E. \& Lucas, R.E. 2007. 'The optimum level of well-being: Can people be too happy?', Association for Psychological Science, 2(4): 346-360.

Parasuraman, S., Purohit, Y.S., Godshalk, V.M. \& Beutell, N.J. 1996. 'Work and family variables, entrepreneurial career success and psychological well-being', Journal of Vocational Behavior, 48(3): 275-300.

Piirala, P. 2012. The impact of entrepreneurial orientation on firm performance: A comparative study of Finnish and German SMEs. Unpublished masters thesis, Aalto University School of Business, Helsinki, Finland. 
Podsakoff, P.M., MacKenzie, S.B., Lee, J.Y. \& Podsakoff, N. 2003. 'Common method biases in behavioral research: A critical review of the literature and recommended remedies', Journal of Applied Psychology, 88(5):879-903.

Rae, D. 2007. Entrepreneurship: From opportunity to action. 1st Edition. New York: MacMillan.

Rahman, S.A., Amran, A., Ahmed, N.H. \& Taghizadeh, S.K. 2013. 'Organizational supports to business success: Ensuring the wellbeing of BoP entrepreneurs', International Journal of Conceptions on Management and Social Sciences, 1(1): 34-44.

Rauch, A. 2000. Success factors of small and medium sized enterprises. Unpublished doctoral thesis, University of Amsterdam, Amsterdam, Netherlands.

Rauch, A., Wiklund, J., Lumpkin, G.T. \& Frese, M. 2009. 'Entrepreneurial orientation and business performance: An assessment of past research and suggestions for the future', Entrepreneurship Theory and Practice, 33(3): 761-787.

Robertson, I.T. \& Cooper, C.L. 2010. 'Full engagement: The integration of employee engagement and psychological well-being', Leadership \& Organization Development Journal, 31(4): 324-336.

Robins, R.W., Fraley, R.C. \& Krueger, R.F. 2009. 'Handbook of research methods in personality psychology', Personal Psychology, 62(1): 189-193.

Rwigema, H. \& Venter, R. 2004. Advanced entrepreneurship. 1st Edition. South Africa: Oxford.

Ryan, R.M. \& Deci, E.L. 2001. 'To be happy or to be self-fulfilled: a review of research on hedonic and eudaimonic well-being', Annual Review of Psychology, 52: 141-166.

Ryff's scale information document. 2016. Obtained through personal contact with Carol Ryff. Unpublished internal information document. Madison: UW-Madison Institute on Aging (IOA).

Ryff, C.D. 1989. 'Happiness is everything, or is it? Explorations on the meaning of psychological well-being', Journal of Personality and Social Psychology, 57(6): 1069-1081.

Ryff, C.D. 2014. 'Psychological well-being revisited: Advances in the science and practice of eudaimonia', Psychotherapy and Psychosomatics, 83: 10-28.

Ryff, C.D. \& Keyes, C.L.M. 1995. 'The structure of psychological well-being revisited', Journal of Personality and Social Psychology, 69(4): 719-727.

Ryff, C.D. \& Singer, B.H. 2006. 'Know thyself and become what you are: A eudaimonic approach to psychological well-being', Journal of Happiness Studies, 8(9): 14-15.

Silwana, H.Z. 2015. The influence of people-centered leadership styles on owner job satisfaction and financial performance: An SME perspective. Unpublished masters dissertation, Nelson Mandela Metropolitan University, Port Elizabeth, South Africa.

Soininen, J., Martikainen, M., Puumalainen, K. \& Kyläheiko, K. 2012. 'Entrepreneurial orientation: Growth and profitability of Finnish small and medium-sized enterprises', International Journal of Production Economics, 140(2): 614-621.
Srimathi, N.L. \& Kiran Kumar, S.K. 2010. 'Psychological wellbeing of employed women across different organisations', Journal of the Indian Academy of Applied Psychology, 36(1): 89-95.

StatSoft. 2013. Statistica (Data Analysis Software System). Version 11. [online] URL: http://www.statsoft.com.

Tabachnick, B.G. \& Fidell, L.S. 2007. Using multivariate statistics. 5th Edition. Boston: Pearson Education.

Techcentral. 2016. Consumer confidence take a battering. 2016. [online] URL: https://www.techcentral.co.za/consumerconfidence-takes-a-battering/66645/.

Teece, D., Pisano, G. \& Shuen, A. 1997. 'Dynamic capabilities and strategic management'. In Kraus, S., Harms, R. \& Fink, M. 2011. 'Family Firm Research: Sketching a Research Field', International Journal of Entrepreneurship and Innovation Management, 13(1): 32-47.

Uy, M.A., Foo, M. \& Song, Z. 2013. 'Joint effects of prior start-up experience and coping strategies on entrepreneurs' psychological well-being', Journal of Business Venturing, 28(5): 583-597.

Venter, R. \& Urban, B. 2016. Entrepreneurship: Theory in practice. 3rd Edition. Cape Town: Oxford.

Winefield, H.R., Gill, T.F., Taylor, A.W. \& Pilkington, R.M. 2012. 'Psychological well-being and psychological distress: Is it necessary to measure both?', Psychology of Well-Being, 2(3): 1-14.

Wright, T.A. \& Cropanzano, R. 2000. 'Psychological well-being and job satisfaction as predictors of job performance', Journal of Occupational Health Psychology, 5(1): 84-94.

Žižek, S.Š., Treven, S. \& Čančer, V. 2015. 'Employees in Slovenia and their psychological well-being based on Ryff's model of psychological well-being', Social Indicators Research, 121(2): 483502. 